\title{
Treatment and Intervention for Opiate Dependence in the United Kingdom: Lessons from Triumph and Failure
}

\author{
Nicola J. Kalk ${ }^{1,2,3}$ (D) - J. Roy Robertson ${ }^{4}$ - Brian Kidd ${ }^{5}$ • \\ Edward Day $^{1} \cdot$ Michael J. Kelleher $^{2} \cdot$ Eilish Gilvarry $^{6}$ • \\ John Strang ${ }^{1,2}$
}

Published online: 28 December 2017

(C) The Author(s) 2017. This article is an open access publication

\begin{abstract}
The history of opiate treatment in the United Kingdom (UK) since the early 1980s is a rich source of learning about the benefits and pitfalls of drug treatment policy. We present five possible lessons to be learnt about how factors outside the clinic, including government, charities and researchers can influence treatment and outcomes. First, do not let a crisis go to waste. The philosophical shift from abstinence to harm reduction in the 1980s, in response to an HIV outbreak in injecting users, facilitated expansion in addiction services and made a harm reduction approach more acceptable. Second, studies of drug-related deaths can lead to advances in care. By elucidating the pattern of mortality, and designing interventions to address the causes, researchers have improved patient safety in certain contexts, though significant investment in Scotland has not arrested rising mortality. Third, collection of longitudinal data and its use to inform clinical guidelines, as pursued from the mid-1990s, can form an enduring evidence base and shape policy, sometimes in unintended ways. Fourth, beware of the presentation of harm reduction and recovery as in conflict. At the least, this reduces patient choice, and at worst, it has caused some services to be redesigned in a manner that jeopardises patient safety. Fifth, the relationship between the third and state sectors must
\end{abstract}

Nicola J. Kalk

nicola.kalk@kcl.ac.uk

1 National Addictions Centre, Kings College London, London, UK

2 South London and Maudsley NHS Foundation Trust, London, UK

3 National Addiction Centre, Institute of Psychiatry, Psychology and Neuroscience, Addiction Sciences Building, 4 Windsor Walk, Denmark Hill, London SE5 8BB, UK

4 Edinburgh University, Edinburgh, UK

5 University of Dundee, Dundee, UK

$6 \quad$ Newcastle University, Newcastle, UK 
be carefully nurtured. In the UK, early collaboration has been replaced by competition, driven by changes in funding, to the detriment of service provision.

Keywords Opiate dependence $\cdot$ Drug policy $\cdot$ Health care services $\cdot$ Recovery agenda $\cdot$ HIV/aids

\section{Introduction}

Over the past few years, public policy towards treatment of opiate dependent patients in the United Kingdom (UK) has changed fundamentally. The politically-driven Recovery Agenda of 2008 onwards, while based on a philosophy with a long history in UK drug treatment (Rolleston Report, Home Office 1926), has led to restructuring of services around detoxification and abstinence, rather than opioid substitution maintenance therapy, in some parts of the UK. For example, financial incentives have been initiated around drug-free discharge from treatment rather than targets in the early 2000 s for numbers of patients engaged in treatment (Duke and Thom 2014). This has diverted attention, and resources, from the more harm reduction orientated treatment system that had evolved over the preceding two decades. It is a useful time for clinicians who were involved in the shaping and implementation of drug policy over this time period to reflect on these changes and on how scientific, political, economic and cultural factors have influenced policy in order to draw generalisable lessons that other clinicians and policy makers may find useful in their development of drug treatment. We intend these lessons to be applicable across health systems, but it is helpful to start our discussion with some particular features of healthcare in the UK (reviewed in Bagott 2015).

Healthcare is funded via general taxation and delivered via services that are free at the point of use. Interventions around drug use include public health interventions aimed at the general population and targeted treatment for dependent populations (see Fig. 1). In the case of drug treatment, services are provided by National Health Service (NHS) Trusts (i.e. the state) and by third sector organisations (that is, adaptations of charities or Non-Governmental Organisations). Devolved administrations such as Scotland and Northern Ireland have responsibility for healthcare policy and funding, so drug treatment policy varies in some respects from England. There is a stepped care system in the UK such that the first point of contact for most problems is in a primary care setting where you may be seen by a generalist doctor called a General Practitioner (GP) or other healthcare professional, who provides a range of treatment. This may include treatment for drug dependence, but as GPs have discretion about whether they provide this treatment, there is variation in service delivery. Patients with more complex problems are referred to secondary addictions services. Here, specialist doctors are usually psychiatrists with a sub-specialist accreditation achieved by spending a year working in an addictions service, or expert GPs with long experience in treating drug dependence.

\section{Opiate Treatment Before 1985}

Problematic opiate use in the UK was first recognised the nineteenth Century (Berridge 1980). Before the 1950s and early 1960s there were very few opiate users, mostly middle aged or elderly, often healthcare professionals, usually using pharmaceutical opiates, in about half of cases initially prescribed for a medical condition (Connell and Strang 2005). The mainstay of medical intervention was intramuscular injection of diamorphine provided by a small number 


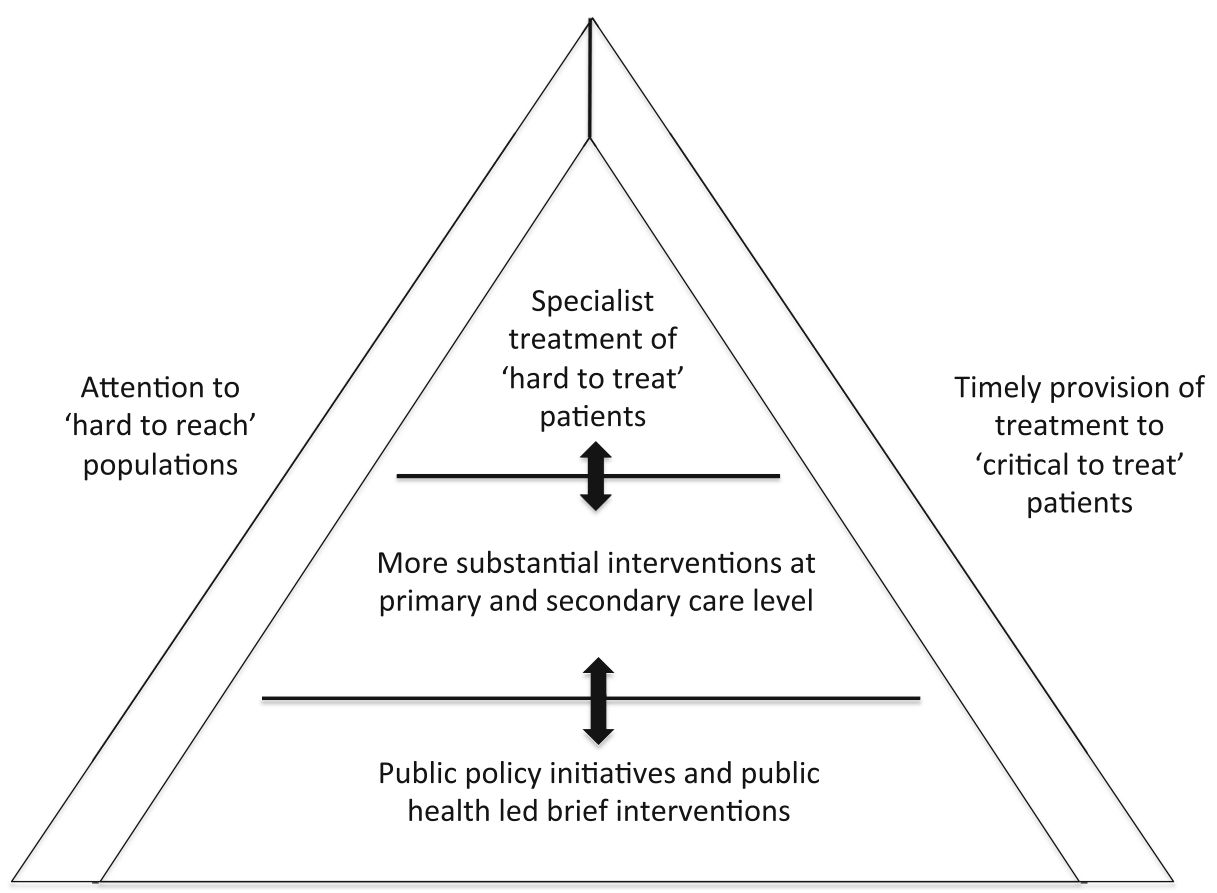

Fig. 1 Schematic diagram of structure of UK Addictions Services

of GPs and this treatment was formally approved in the context of an overall plan of care (Home Office 1926). The 1960s heralded an explosion in experimentation with drugs by young people: the number of new non-therapeutic heroin addicted patients grew from 23 in 1960 to 1304 in 1968 (Bewley 2005). They used diverted pharmaceutical heroin as part of a wider pattern of drug use, which they increasingly injected intravenously. They were viewed as a threat to public order because of their numbers and their youth. A number of doctors who prescribed diamorphine liberally with few controls to addicted patients appeared to contribute to this increase (Mitcheson 2005). Therefore, following the recommendations of an expert committee, prescribing of opiate substitution was restricted to specialists (Ministry of Health 1965). As a consequence, around 20 Drug Dependency Units were established in 1968 across the UK, linked to teaching hospitals (Willis 2005). Methadone, predominantly administered intramuscularly, was prescribed and over time replaced prescribed heroin as substitution treatment (Willis 2005). At the same time, residential rehabilitation facilities were established by the third sector. These were often initiated or supported by psychiatrists (Turner 2005). Through the latter part of the 1970s and early 1980s, disillusionment set in (Paxton et al. 1978) and there was an explicit move away from maintenance in all forms, as captured in the report the Advisory Council on the Misuse of Drugs (ACMD), an expert committee who advised the government about drug policy, and the later Department of Health guidelines (ACMD 1982; Department of Health 1984). By the early 1980s, there was 'therapeutic anarchy' (Strang et al. 2005, p. 3) as prescribing practices, goals of treatment and interpretation of, the largely United States evidence base, were so variable. 


\section{Lesson 1: Do Not Let a Crisis Go To Waste}

\section{'The spread of HIV is a greater danger to individual and public health than drug misuse' (ACMD 1988)}

The 1980s saw a sea change in drug policy as abrupt as it was extensive. Its origins lay in the discovery of an epidemic of HIV infection among people who inject drugs in Edinburgh and Dundee (Robertson et al. 1986; Burns et al. 1996). This was quickly followed by emerging evidence of HIV spread among drug users in other European cities (Robertson 2005). Around the same time, the potential for heterosexual transmission was recognised. As the international community focused more and more on the scale of the African epidemic it became apparent that the largely heterosexual, drug using population could represent a reservoir of infection that could affect the general community via sexual contact. Serial International AIDS Conferences began to explore the world wide epidemiological consequences of HIV among young men and women sharing injecting equipment in an uncontrolled way. Prior to this, the virus had been considered a disease restricted to the gay community. People who inject drugs were thus of major interest and concern for public health and public safety, since they might represent a reservoir of infection that could transmit HIV to the wider community. This received immediate attention in the media, and rapidly became a problem of national concern.

A shift on this scale is unusual, as policy usually evolves in small increments (Bagott 2015). To make sense of the changes, Kingdon (Kingdon 2014) breaks down policy shifts into three 'streams': the problem stream, the policy stream and the political stream. The problem stream related to how the drug problem was framed. By reframing the policy 'problem' of drug users - not as a public order issue, but rather a public health issue - doctors were able to propose a solution to the problem that would have previously lacked widespread support. This was a new 'policy stream', which involved 'stepping aside from moral judgement. The advocate of harm reduction was neither for nor against personal freedoms; neither for nor against changes in the legal status of drug use; neither for nor against changes in treatment provision - except insofar as they could be shown to have a direct relationship to the amounts of harm which resulted for an individual and for society' (Strang 2005, p. 197). This approach was made explicit at the Stockholm conference on AIDS in 1988 which included the research from Edinburgh, and interested parties from the WHO and United States. Professor Robertson recalls that the chairman of the conference read a statement recommending the sanctioning of harm minimisation interventions such as needle exchange and methadone without any hindrance. That same year, the ACMD report 'AIDS and Drugs Misuse' stated that HIV posed a greater risk to public health, and set out the components of harm reduction (ACMD 1988). This statement from an independent expert advisory committee had a substantial impact on subsequent opiate treatment policy.

Harm reduction had not previously been perceived by the press or politicians (Kingdon's political stream) as a legitimate objective of medical treatment. Indeed, the descriptive term 'harm reduction' was not in use prior to the second half of the 1980s (Strang and Gossop 2005). However, in private the relationships between clinicians, researchers and policy makers - both civil servants and politicians - were open to new ways conceptualising the purpose and benefits of treatment. Pragmatic decisions could 
therefore be taken following discussions that would become politicised in public, for example in allowing pilot needle exchange schemes, initiated by the third sector, to continue and evaluating them (Sheridan 2005). Policy makers were also motivated to understand the problem: for example, the government minister Norman Fowler visited San Francisco to investigate the potential impact of HIV. Roy Robertson recalls a steady stream of civil servants, academics and media people visiting his Edinburgh GP surgery to explore the developing story of HIV among drug users, and their partners and children. The spectre of a national AIDS epidemic in the general population helped to sharpen the minds of politicians and civil servants and motivated the funding of methadone maintenance treatment and expansion of services. The media also played a role in redirecting the political stream, as it reinforced the idea of heroin use as a threat to 'ordinary' young people, such as widely reporting the case of an Oxford student, the daughter of an MP, who died of heroin overdose (Daily Mail 2007). Dr. Kidd recalls that some societal unease about methadone did remain: local community pressure groups in Glasgow canvassed the local health board in an attempt to prevent the introduction of methadone prescribing. Nonetheless, funding for drug services increased from $£ 5.235$ million to $£ 8.239$ million per year between 1987 and 1993 and funding for care targeting HIV positive people who used drugs increased from $£ 1.132$ million per year to $£ 16.132$ million in the same period (Stimson 1995). There was also a lack of constraint placed upon the form of drug treatment services by the government which facilitated reorientation around the harm reduction approach (Stimson 1995).

Harm reduction proved effective. The approach was broad-based, and included the provision and expansion of opiate substitution treatment, needle exchange and education regarding safer injecting techniques. Needle and syringe sharing causing HIV transmission in people who inject drugs in Edinburgh peaked in 1980-1982 (Robertson 2005) and dropped from peak levels of 55\% to $20 \%$ by 1993 (Stimson 1995). The UK avoided the rapid rise in HIV seen in other countries. HIV remained rare among people who inject drugs in cities in the UK compared to elsewhere in Europe: $12.8 \%$ in London, $1.8 \%$ in Glasgow compared with $20 \%$ in Rome and $60 \%$ in Madrid (WHO Collaborative Study Group 1993). This related to large changes in risk behaviour such as frequency of injection and needle sharing in the injecting population (Skidmore et al. 1989). In contrast, evidence from the United States suggests that policies incorporating a less accepting stance towards injecting such as the policy of 'punish to deter' drug injecting resulted in more risky practices (Bluthenthal et al. 1999).

An accompanying culture change occurred: 'prescribing substitute drugs...was transformed from a shady pastime...to a well-supported clinical priority’ (Robertson 2005, p.131), though some doctors continued to stigmatise drug users and were reluctant to prescribe methadone (Kidd and Ralston 1993). Methadone maintenance was found to be associated with a reduction in HIV transmission (Metzger and Zhang 2010). The ACMD recommended the expansion of needle exchange schemes from 15 to 200 by 1990, and in 1993 it stated that structured oral methadone maintenance programmes were a fundamental part of the response to HIV (ACMD 1993). In Scotland, a 1994 strategy report made harm reduction the focus of drug treatment and brought the first real Scottish national investment in addictions (Scottish Office 1994). Thus, addictions experts were able to harness the HIV outbreak to motivate for investment in services for their marginalised group of patients, leading to a massive expansion of services and acceptance of controversial, though evidence-based, interventions. They did not let a crisis go to waste. 


\title{
Lesson 2: Understanding Patterns of Mortality in Fine Detail Saves Lives
}

\author{
'Death matters.' (Strang 2015)
}

Prediction of drug-related death is scientifically very difficult. Such deaths are rare events and multiple factors are at play in a heterogenous group exposed to many risks. However, active research investigating how deaths related to opiates cluster in time in space since the mid 1990s has led to the design and implementation of targeted interventions (reviewed in Strang 2015). The focus on mortality was born of a recognition that opiate-related deaths are disproportionately high in relation to the proportion of the population who use opiates (though used by $0.3 \%$ of the population, opiates are linked to $85 \%$ of drug-related deaths) (Strang 2015). The situation was complicated by concern over an increase in drug-related deaths, particularly where prescribed methadone was mentioned, during the period of expansion of drug services (Hall et al. 2000). Diversion of prescribed methadone seemed to account at least in part for the death rate (Strang 2015). At the time, more than a third of methadone prescriptions were picked up weekly to fortnightly and there was no supervised consumption (Strang et al. 1996a, b).

The practice of supervising methadone consumption addressed the issue of diversion and improved compliance with treatment and was initiated in 1992 in Scotland (Scott et al. 1995). Nationally, pharmacists were already involved in providing clean injecting equipment and dispensing methadone and were open to the idea of supervision (Luger et al. 2000). The third edition of national guidelines on drug treatment (Department of Health 1999) recommended supervised consumption during the early months of maintenance, and led to the establishment of supervised dosing in just over a third (36\%) of community pharmacies by 2005 (Strang et al. 2007). The presence of the researchers who had investigated heroin mortality on the expert committee that produced the guidelines facilitated swift translation of the evidence into practice. The policy was a success as it was associated with a reduction from 19 to 4 deaths per million daily prescribed doses in Scotland, and from 25 to around 6 deaths per million daily prescribed doses in England (Strang et al. 2010). This improvement occurred at the same time as a recommendation that methadone doses should, ordinarily, be titrated up to a minimum of $50 \mathrm{mg}$ per day, which led to an increase in the mean dose of methadone prescribed (Strang et al. 2010).

A further important step was the identification of a time-related cluster of opiate overdose was identified following prison release. In the early 2000s, initial research in Scotland (Bird and Hutchinson 2003) (and later confirmed in England and Wales) showed a sevenfold increase in overdose death in the fortnight following release (Farrell and Marsden 2008). This data was used to persuade policy makers that drug treatment services needed to be developed in prisons (Strang 2015). The provision of opiate substitution treatment after 2002 was associated with a fall in overdose deaths in the first three months following release from 3.8 per 1000 releases to 2.2 per 1000 releases (Bird et al. 2015).

Other insights into drug-related death, and possible preventative measures, have emerged from studying clustering of cases. First, it was found that $30 \%$ of injecting users had experienced a non-fatal overdose, compared with only $2 \%$ of those who inhaled heroin (Gossop et al. 1996) suggesting the risk is largely limited to the injecting route. Second, it was established that most took place at home or a friend's home, and the majority were witnessed (Strang et al. 1999). This led to a novel intervention: 'take home naloxone' (THN) 
(Strang et al. 1996a, b). Naloxone was already administered in emergency care settings to reverse opiate overdose. The idea of THN was that it could be used by lay persons in a similar manner to an epi-pen for treatment of anaphylaxis. Scotland has recently become the first country to roll out take-home naloxone as national policy with dedicated funding in 2011 (McAuley et al. 2012) and a similar scheme was implemented at around the same time in Wales (Bennett and Holloway 2012; McDonald et al. 2016). THN provision prior to release from prison has been associated with a $36 \%$ fall in opiate overdose death in the four weeks following release (Bird et al. 2016).

The Scottish government report in 2003 was the first national attempt to investigate drugrelated deaths in a systematic way (Zador et al. 2003) and subsequently such data has been collected annually. Additional insights about elevated risk of death in opiate users has resulted from this, for example, most people who die of overdose take more than one substance: alcohol was found in $50 \%$ of patients who died of an opiate overdose, and benzodiazepines in $33 \%$ (Zador et al. 2003). Only 20\% were in contact with drug treatment services in the preceding six months. There has subsequently been significant Scottish investment around prevention of drug-related deaths. Despite this, drug-related deaths in Scotland have continued to rise, although not at the rate that they have recently risen in England (Office of National Statistics 2015). Recent research into methadone-related deaths suggests that standard doses of methadone may be more toxic in 'older' drug users, that is those over 35 years, possibly because of progressive comorbid liver conditions (Gao et al. 2016), a finding which may impact prescribing practice. A continued barrier to prevention continues to be lack of engagement with treatment services - recent figures suggest that only $47 \%$ of those who died of overdose were in contact with treatment (Barnsdale et al. 2016).

\title{
Lesson 3: An Emphasis on Outcomes Monitoring, Research and Guidelines Creates a Bed Rock of Best Practice and Can Shape Policy, Even if Sometimes in Unintended Ways
}

\author{
'Treatment works' (Department of Health 1999) \\ 'A Cochrane systematic review strives to present the whole picture, and do so in a way \\ that invites critique and improvement. This puts vested interests to one side, and can \\ only benefit the consumer.' (Leighton and Day 2013, p.19)
}

The initiation of specialist drug services in the 1960s and 1970s, and their expansion in response to the HIV crisis in the 1980s, as well as the explicit recommendation by the 1982 ACMD report that GPs take on the challenge of drug treatment, led to greater involvement of an inexperienced and non-specialist work-force (Merrill and Ruben 2005). Therefore, the ACMD recommended the development of best practice guidelines in 1982 (ACMD 1982). The first 'Orange Guidelines' — so-called because of the colour of the booklet - were published in 1984 and distributed free to GPs, with the explicit endorsement of the Chief Medical Officer (Merrill and Ruben 2005). The Orange Guidelines have been periodically updated and re-written (1991, 1999, 2007, 2017). They are distinctive, differing from other guidelines produced subsequently in other fields in UK healthcare in that they are a pragmatic, how-to guide written in accessible language. They contain not only summaries of formal reviews of the research evidence 
but also very practical material, for example, a step-by-step diagrammatic guide for the cleaning of injecting equipment (see Fig. 2) (Department of Health 1991).

The initial guidelines relied mainly on expert opinion to reach a consensus as the research base was limited. The group of experts producing them were both aware of the small international evidence base and actively involved in producing relevant research in the UK, so were in an ideal position to translate research findings quickly into practice recommendations. By the third edition published in 1999, the volume had expanded and referenced the growing evidence base affirming the effectiveness of harm minimisation strategies. In 2007, the process was supported by the commissioning of systematic reviews of the research evidence base, which were completed by the National Institute for Health and Clinical Excellence (NICE). NICE Guidelines and Technology Appraisals covering all the key medical and psychological interventions were considered by the guideline group (NICE 2007a, b, c, d). Thus the rapidly expanding, increasingly robust, evidence base underpinning drug treatment was analysed and consensus reached regarding best practice in assessment and pharmacological, psychosocial and general health assessment and interventions for drug dependent patients.

The Orange Guidelines continue to be the main source of drug treatment knowledge for the workforce, as many drugs workers do not have any field-related training when they are first employed, so may lack expertise in managing mental and physical health comorbidity and aspects of pharmacological treatment (Boys et al. 1997). Similarly, doctors, even those specialising in psychiatry, and nurses, are not given much training

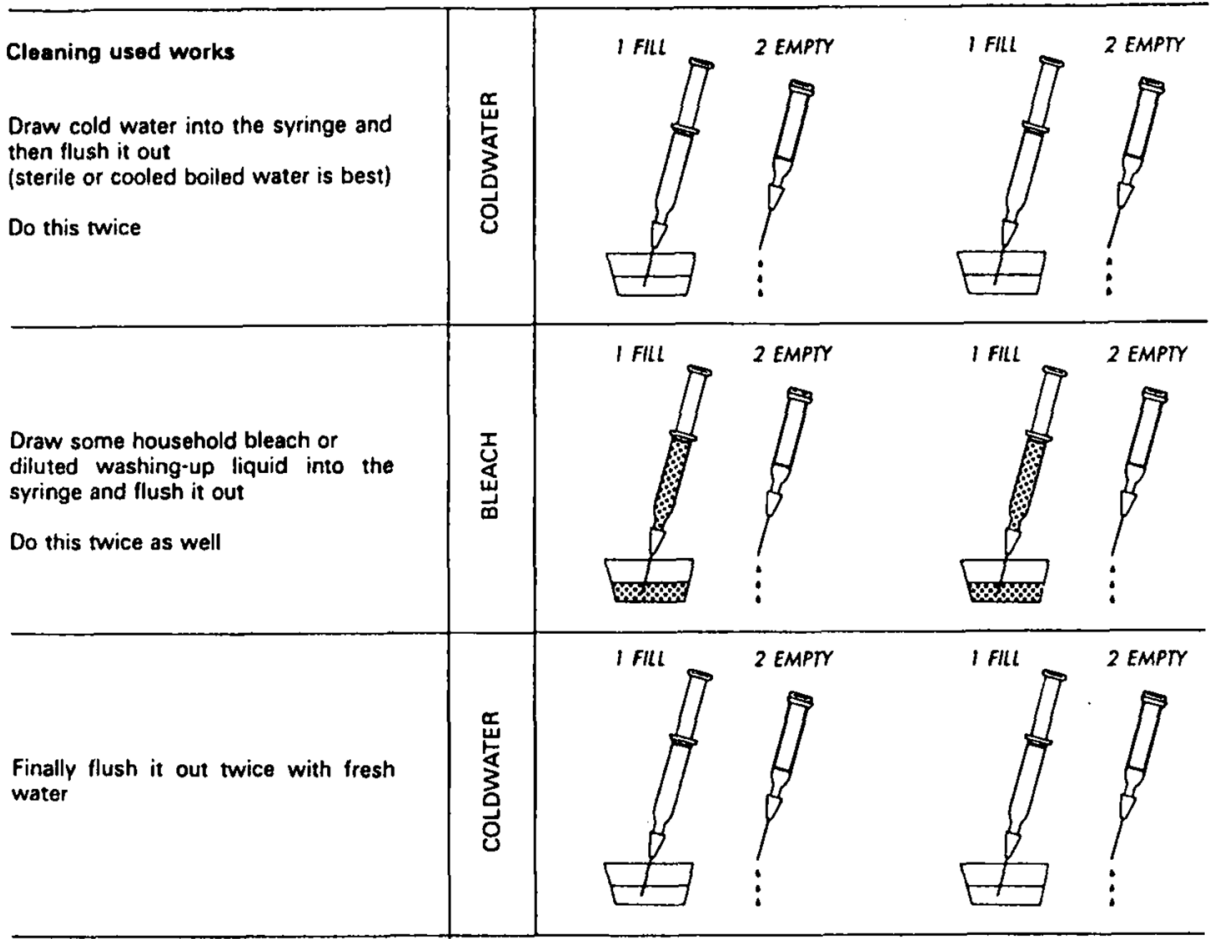

Fig. 2 Diagrams explaining how to clean injecting equipment from second Orange Guidelines (reproduced from Strang 1998) 
in addictions (O'Gara et al. 2009). The number of specialist addiction psychiatry training posts increased dramatically between 2000 and 2008, but has now started to fall again in England (from 52 in 2006 to 26 in 2014) as the treatment sector is moved out of the NHS (see below) (Drummond in Mohammadi 2015). This is in contrast to Scotland, where services have remained within the NHS and training posts have not reduced as much (from 11 to 9 in 2015) (Drummond 2015). A continued challenge, perhaps related to the dearth of training, is the failure of services to implement the Orange Guidelines fully. For example, the majority of prescribed doses of methadone continue to fall below the bottom of the recommended therapeutic range (Strang et al. 2007). There are therefore currently efforts to develop an online course based on the guidelines in order to increase engagement and familiarity with them among drug workers.

The period of treatment expansion in the 1990s also gave rise to large-scale longitudinal research studies, the first of which was the National Treatment Outcomes Research Study in England (NTORS). Ministerial anxiety that the balance was insufficiently towards abstinence-based treatment, and concern that methadone treatment was just replacing one addiction with another, motivated the creation of a government task force in 1994 (Gossop 2015). The chairman, Reverend Polkinghorne was a theoretical physicist who was comfortable evaluating scientific evidence (Polkinghorne et al. 2005). He decided that a large prospective study would be required to evaluate the progress of patients in clinical treatment and commissioned NTORS. It was a prospective longitudinal study of 1075 patients entering 54 treatment services in England, utilising one of four different treatment modalities: residential rehabilitation, in-patient detoxification, methadone detoxification treatment and methadone maintenance treatment. It was modelled on prospective studies of the impact of drug treatment from the United States carried out in the 1980s and 1990s. The final assessments occurred five years after initial recruitment, and to date, it is the largest and longest follow up study of opiate users in the UK (Gossop 2015). NTORS demonstrated impressive retention of participants, but it was subject to the pitfalls of any prospective observational study comparing outcomes. First, they are subject to selection bias: it is difficult to compare groups who choose different treatments and may vary in terms of complexity and chronicity of drug dependence. Second, although observations are repeated over time, they still capture a 'snapshot' of the patient's functioning, which in a relapsing remitting condition such as drug dependence, can misrepresent the clinical course. Third, the number of different services involved in NTORS raised the possibility that differences in service culture, process or performance may have impacted on outcome. Nevertheless, NTORS provided, for the first time in the UK, large - scale follow-up data on a range of types of treatment alongside individual analysis of outcome - and it profoundly contributed to political, public and policy decisions.

Key findings from NTORS were that illicit drug use and risk behaviours such as injecting and sharing injecting equipment were significantly reduced at 1 year, and this improvement was maintained 5 years later (Gossop et al. 2003). Major differences between treatment modalities were identified, most notably that methadone maintenance was associated with a greater propensity for engagement and retention in treatment than methadone detoxification (Gossop 2015). The NTORS research team provided interim reports to the Task Force, which encouraged the Department of Health to extend the funding to facilitate 5 year follow up. Although the Task Force had disbanded by the time the results of the final evaluation were available, it was able to draw on the interim 
findings to provide policy recommendations. The report, published in 1995, concluded that 'treatment works', that is, that treatment could produce significant and cost-effective reductions in harms to the patient and society. The report noted that recovery seemed an incremental process, and that a prompt response to presentation was important because of the relapsing remitting nature of the clinical course. Ultimately, it contributed to an immediate increase in funding of six million pounds, to develop programmes that involved methadone maintenance more explicitly (Polkinghorne et al. 2005).

The relationship between opiate use and crime was also explored in NTORS which influenced policy in an unanticipated manner. NTORS provided evidence to inform political attention to crime reduction which resulted from drug treatment. The authors found that 27,000 crimes had been committed in the three months before entering treatment. During treatment, the number of crimes committed fell by two thirds and criminal involvement halved (Gossop et al. 2000). The cost-saving implications were substantial: every $£ 1$ spent on treatment saved at least $£ 3$ spent on crime (Gossop et al. 2000). This provided a new impetus for drug treatment expansion, as the government of the day aspired to be 'tough on crime, tough on the causes of crime' (Blair 1993). This led to the development of Drug Treatment and Testing Orders, an alternative to incarceration which involved attending drug treatment for six months to a maximum of three years, with compulsory urine testing and regular reporting to the courts (Finch and Ashton 2005). Take up in areas piloting the system was initially modest and reflected in part, mixed feelings among staff about 'consent to treatment under duress' and mixed feelings among offenders, some of whom felt that prison was the 'easier option'. Nonetheless, a new avenue to treatment entry had been identified and by $2009,35 \%$ of drug users entering treatment arrived via criminal justice routes (Jones et al. 2009). Critics of the policy were concerned about the impact of perceived coercion into treatment and diversion of resources away from non-offending drug users (Finch and Ashton 2005).

The Drug Outcomes Research in Scotland (DORIS) study was commissioned by an independent trust designed along the lines of NTORS, but focussed on abstinence (McKeganey et al. 2006). A strength of DORIS relative to NTORS was that there were no differences in clinical characteristics of patients accessing different forms of treatment. The authors found that $88 \%$ of respondents had used heroin in the 90 days prior to the 33 month follow up assessment. Only 5.9\% of females and 9\% of males were abstinent at 33 months follow up and this group was heavily skewed towards those who had been accessing residential rehabilitation programmes. The proposed direction of causality was that abstinence led to other benefits, though others have challenged this, suggesting reverse causality or other mechanisms (Ashton 2008), as abstinence was measured over the preceding three months and other outcomes over the past 17 . Crucially for subsequent policy arguments, $57 \%$ of patients reported that abstinence was their primary aim in entering treatment. Others have pointed out that $44 \%$ of the sample were entering a modality of treatment where abstinence was the only available end-point (for example, abstinence-based programmes or in prison where only detoxification was available) (Ashton 2008). Nonetheless, the authors concluded that more funding for residential rehabilitation was necessary and that "there is a need to establish why so few drug users in contact with the methadone programme in Scotland appear able to become drug free 33 months after having contacted this service”. Thus longitudinal studies, which were initially commissioned to provide evidence to support methadone maintenance treatment and did so when success was framed in terms of reduction in drug-related harms, in the end contributed to the rise of Recovery Movement, which has precipitated a shift away from maintenance in favour of abstinence-orientated treatment. 


\title{
Lesson 4: Beware the False Dichotomy Between Harm Minimisation and Abstinence
}

\begin{abstract}
"Harm reduction has often been made an unnecessarily controversial issue, as if there were a contradiction between treatment and prevention on the one hand and reducing the adverse health and social consequences of drug use on the other. This is a false dichotomy. They are complementary." (UNODC 2008, p.2)
\end{abstract}

'It is a well-known fact that methadone is more addictive than heroin; yet this is virtually the only option open to many drug addicts across Scotland. Every pound spent on this so-called harm reduction route is a pound not spent on rehabilitation and the real fight against drugs' Annabel Goldie, Member of Scottish Parliament (McKeganey 2014).

'The treatment which across the world has done most to curb addiction (leading to methadone's designation by (the) World Health Organisation as an 'essential medicine') and with almost certainty crime was portrayed as sustaining both; ally had become enemy' (Ashton 2008)

The concept of recovery in some form has always been part of the philosophy treatment services and was clearly articulated as an aim in the Rolleston Report - a report which also makes harm reduction goals central to treatment delivery, even though the term itself was not in use at that time (Home Office 1926). It was also a central part of the original articulation of opiate substitution therapy. With the expansion of methadone maintenance treatment from the 1980 s on, it seems that this was lost, at least in some places. Although the 2007 Treatment Guidelines delineated a cascade of drug treatment aims, from initial harm reduction and stabilisation using opiate substitution to eventual abstinence, or full recovery (Department of Health 2007), the 2000s and early 2010 s were marked by an increasingly polarised debate where methadone maintenance was seen as antithetical to a goal of abstinence (Ashton 2008). This shift has been attributed to a growing criticism of opioid substitution treatment from, and influence of, a centre right think-tank, the Centre for Social Justice, Conservative politicians and rightwing press, certain researchers and providers of residential rehabilitation (Duke and Thom 2014). At the same time, this was exacerbated by resentment regarding the priority given to scientific evidence over the lived experience of drug treatment providers and patients (Duke and Thom 2014). The DORIS study finding that the majority of people had a goal of achieving abstinence on entering treatment but few achieved it (McKeganey et al. 2004) was used to redefine the 'problem stream' in the drug policy discourse (Kingdon 2014). Whereas methadone had been seen as the solution to the problem of injecting drug use and associated risks, it was now framed as a 'failing treatment', (Duke and Thom 2014, p968). The proposed solution, or the associated 'policy stream', was the refocussing of treatment services around recovery - the socalled recovery agenda. In parallel, there was a growing impetus in the 'political stream', comprised of the conservative think-tank Centre for Social Justice, the Scottish Conservative party and the media, all largely critical of methadone maintenance (Duke and 
Thom 2014; McKeganey 2014). The leader of the Scottish Conservative Party, Annabel Goldie, referred to people being 'parked on methadone', evoking the image of a parking lot where patients remained in stasis rather than moving on to a better life. There was also a growing resentment towards the primacy of scientific evidence (Duke and Thom 2014), and the perceived exclusion of the lived experience of patients and experiential knowledge of addictions service staff as valid bases for treatment planning (Glasby 2006 in Duke and Thom 2014). The stage was set for large scale policy change.

The recovery agenda acknowledged that pragmatism and harm reduction should be accompanied more explicitly by aspiration for patients. This is captured explicitly and positively in the Public Health England Report 'Medications in Recovery (2014) and the Scottish Government document 'Road to Recovery' (Scottish Government 2008). The PHE report was itself as a result of, and a reaction to, government pressure to challenge the role of medications in treatment programs. Clinicians from across the field, including abstentionists and harm reductionists, also published a consensus document regarding the definition of recovery (UK Drug Policy Commission 2008) — but even this remained open to debate and the subject of some dispute. It is clear that recovery had different meanings to different groups, as the difference in interpretations by Scottish and English governments described below illustrate. In particular, the place of medications such as opioid substitution therapy and take-home naloxone within recovery-orientated services appears controversial despite the evidence base, as explored below.

Although all the government policy documents have acknowledged that harm reduction and recovery are not mutually exclusive, actual implementation of the policy has varied in England and in Scotland. In Scotland, the government has remained receptive to the opinion of experts that harm reduction generally and methadone maintenance in particular is a central element of treatment. However, recent reviews of Scottish performance in this regard show that little improvement has been delivered (Scottish Drug Strategy Delivery Commission 2013). In England, on the other hand, recovery has often been equated to abstinence. This is strikingly captured in the government document 'Putting full recovery first' (Inter-Ministerial Group on Drugs 2012) in which it is clear that little value is placed on anything short of the 'full recovery' which government ministers describe. This assumption that recovery equals abstinence is also evident implicitly in the way the policy has been implemented. For example, $20 \%$ of funding is determined by the numbers of patients being discharged drug free and not returning to treatment for six months (National Treatment Agency for Substance Misuse 2012). Evaluation of UK funding based on drug-free treatment completion has suggested that it has been associated with a 'greater emphasis... on promoting the staged reduction of opioid substitution dosage to both new and existing service users' (Disley et al. 2014, p.6). This appears, at least until recently, to reflect the political ideology of influential figures within the current Conservative government and not the evidence base derived from the world literature.

The recovery agenda has influenced the culture of services and the beliefs of patients. In the minds of many prescribers and drug users methadone has been demonised and is associated with failure rather than secure stability. Qualitative research has identified that patients are likely to hasten their detoxification from methadone, carrying a risk of relapse, because they want to hasten their recovery (Neale et al. 2013). The take-up of Take-Home Naloxone (THN) provision on prison release has also been impeded by views of both patients and staff that accepting THN is antithetical to a commitment to recovery (Sondhi et al. 2016). Thus, despite the positive idea of recovery and the concept of a recovery journey from harm reduction to abstinence, with a place for medication, 
being made explicit in the policy documents, the actual implementation of a recovery agenda, by which we mean the way in which it has been distorted and internalised in a concrete way by staff and patients, has sometimes resulted in damaging changes with associated risks.

\section{Lesson 5: Beware Competitive Tendering: Commissioning for Drug Treatment Services Erodes Co-operation Between Statutory and Third Sectors}

In the 1960s and 1970s, the relationship between third sector and statutory sector drug services was mutually supportive as the services they provided were complementary: whereas NHS drug teams provided OST, third sector providers provided advice and aftercare such as residential rehabilitation. In some cases, the establishment of rehabilitation facilities was actively supported by the NHS: for example, Phoenix House in South London was founded with active effort from Griffith Edwards, a leading NHS psychiatrist, and the site gifted to them by the local psychiatric hospital (Strang 2010) and this was the case for many residential and community third services. It was not uncommon for doctors employed in NHS treatment services to sit on the boards of third sector services.

A major change has occurred in the relationship between statutory and third sectors. This is almost certainly related to changes in healthcare funding that commenced in 1989 through the Department of Health's White paper "Working for Patients" driven by the ideas of Alain Enthoven, an American economist whose research has focused on increasing healthcare quality while reducing costs (Enthoven 1985). The NHS had until that point been driven by central planning, and funding was often unrelated to need. At the time there were variations in quality of care and long waiting lists for surgery. The problem was framed as the result of absence of incentives for efficiency (Maynard and Dixon 2016) and the introduction of an internal market as a solution became a manifesto pledge and key issue in the 1987 election. Over subsequent years a purchaser-provider split was introduced, with greater emphasis on local areas taking greater control through active commissioning in order to maximise efficiency. In this model, local commissioning groups assessed the needs of the population and provided funding for specific healthcare in a tailored way (Bagott 2015). In the early years of this century the British government greatly increased investment in addiction treatment. However, such funds were attached to a rigorous performance framework based on waiting times, numbers in treatment and outcomes (as measured by the Treatment Outcome Profile).

Initially commissioners funded statutory NHS services to provide pharmacological treatment, including in-patient detoxification, whilst third sector services provided advice and psychosocial interventions as well as residential rehabilitation (Turner 2005). Over time, and particularly from the late 2000 s onwards, clinicians based in statutory services noticed a difference in the behaviour of third sector organisations. Instead of providing collaborative services, they began to bid, increasingly successfully, to take over existing NHS treatment services. There were many reasons for this; some NHS services were unresponsive to the needs of local communities and slow to react to a performance driven framework for the provision of services in England. Third sector organisations were often more responsive to the needs of local commissioners, who were themselves performance managed by a central special health authority - the National Treatment Agency. NHS clinicians were surprised by this move from collaboration to competition. For example, Professor Strang recalls resigning from 
his position on the board of a third sector organisation when he discovered that he was part of a bid to take over a detoxification unit within his NHS organisation.

Proponents of commissioning argue that there have been benefits to such changes in commissioning processes, including expansion of provision, greatly reduced waiting times for treatment, and a more responsiveness to local needs. That said the move of the third sector into being in competition with, instead of complementary to, NHS providers has had several negative outcomes. Firstly, the identified strengths of the third sector have historically been to be innovative and locally responsive (Turner 2005). In order to comply with the clinical governance structures in the NHS and to tailor their bids to the requirements of clinical commissioning groups, this distinctiveness is much reduced (Turner 2005). Furthermore, the complementarity of service provision between the sectors is threatened, even though some examples still exist of new ways of working through consortia that preserve and value the wider reach of a collaborative statutory-third framework (Strang et al. 2014). Secondly, with the disappearance of the NHS addiction services from swathes of England - for instance there is no NHS addiction provision in Birmingham, a city with a population of 1 million people there has been a reduction in the numbers of doctors and allied healthcare professionals being trained in addictions treatment (Drummond 2015). Thirdly, in the English context of commissioning, regulation of healthcare up until recently has often been weak (Francis 2013). This can lead to a situation where services with less qualified staff win tenders whose outcome is largely driven by price: for example, Dr. Kelleher notes that there is currently no fully medically staffed unit (outside of private medicine) in London where planned detoxification can take place). Fourthly, third sector providers lack NHS insurance, so the opportunities for research are reduced. Recently, competitive tendering of addiction services on price, associated with a crisis in the overall funding of the NHS has led to a situation where significant sums of money are removed from addiction treatment contracts - 30\% is not unusual (for example, Stoke Sentinel 2016). This has had the perhaps ironic consequence that over recent months what remains of the NHS is again collaborating with the third sector (collective voice) to raise awareness about such cuts.

\section{Conclusions}

UK experience in the development of drug treatment services shows that clinical risks, affecting the wider population can sometimes be harnessed to fund and optimise treatment for marginalised groups. It is therefore recommended that new services in countries with nascent drug problems should be structured in a way that facilitates data collection and research. Monitoring physical health outcomes related to drug-taking, such as prevalence of blood borne viruses, seems particularly important. Clinicians should recognise that they, and clinical research, represent only one perspective or interest group, and that political decisionmaking involves other concerns. However, scientific evidence remains a powerful justification for policy changes and should be used vigorously to influence policy directions. We would encourage policy-makers to foster links with clinicians and researchers, and encourage both to retain an open mind, in order to understand the evidence base and guard against sentimentdriven policy making.

Many of the key insights about the effectiveness of opiate substitution therapy in the UK emerged from government-funded longitudinal studies. Government-backed research councils also funded research into opiate-related deaths. We would recommend that policy-makers 
consider commissioning similar studies as this provided valuable insights into the way services should be structured. Both broad longitudinal studies, similar to NTORS, and more targeted hypothesis-driven studies, such as Bird and colleagues' (Bird et al. 2016) evaluation of the introduction of naloxone on prison release, are likely to be of value. Similarly, having in place mechanisms that can translate the emerging evidence base into clinical guidelines increases the possibility of improvement in patient care. One way in which policy-makers and guidelines committee members could improve on the UK model is by embedding a strategy for dissemination and training in the guideline development remit with broad national reach, for example via e-learning, and incentives such as linking to staff appraisal.

Drug treatment policy is emotive and influenced by societal mores. Clinicians, researchers and policy-makers should guard against black and white thinking and the development of destructive false dichotomies, such as the oppositional approach seen with harm minimisation and recovery. It should be emphasised in clinical, policy and public circles, that harm minimisation and recovery represent points on a continuum. Finally, drug treatment in the UK owes a lot to early innovation in the third sector. Third sector and statutory sector clinicians should strive to collaborate based on their complementary respective strengths. Policy makers should be aware of how funding changes can influence service design and relationships between service providers, with associated risks to the standard and breadth of provision. In particular, a move towards competitive target driven markets can be seen to have benefits in increasing productivity, but without proper regulation there can be a drive to reduce healthcare spending with a commensurate reduction in quality.

Open Access This article is distributed under the terms of the Creative Commons Attribution 4.0 International License (http://creativecommons.org/licenses/by/4.0/), which permits unrestricted use, distribution, and reproduction in any medium, provided you give appropriate credit to the original author(s) and the source, provide a link to the Creative Commons license, and indicate if changes were made.

\section{References}

Advisory Council on the Misuse of Drugs. (1982). Treatment and rehabilitation. London: Her Majesty's Stationary Office (HMSO).

Advisory Council on the Misuse of Drugs. (1988). AIDS and drug misuse, part I. London: HMSO.

Advisory Council on the Misuse of Drugs. (1993). AIDS and drug misuse update report. London: HMSO.

Ashton, M. (2008). The new abstentionists. Druglink Special Insert Dec/Jan 2008. http://www.drugwise.org. uk/wp-content/uploads/New-abstentionists.pdf Accessed 19 Dec 2016.

Bagott, R. (2015). Understanding health policy. Bristol: Policy Press.

Barnsdale, L., Gordon, R., Graham, L., Walker, D., Elliott, V., Graham, B. (2016). The National Drug-Related Deaths Database (Scotland) Report: Analysis of deaths occurring in 2014. NHS Scotland. http://www. isdscotland.org/Health-Topics/Drugs-and-Alcohol-Misuse/Publications/2016-03-22/2016-03-22-NDRDDReport.pdf. Accessed 9 Dec 2016.

Bennett, T., \& Holloway, K. (2012). The impact of take-home naloxone distribution and training on opiate overdose knowledge and response an evaluation of the THN project in Wales. Drugs: education, prevention and policy, 19(4), 320-328.

Berridge, V. (1980) The making of the Rolleston report: 1908-1926. Journal of Drug Issues, Winter, 7-28.

Bewley, T. (2005). The drug problem of the 1960s: A new type of problem. In J. Strang \& M. Gossop (Eds.), Heroin addiction and the British system (Vol. I, pp. 43-52). Oxford: Routledge.

Bird, S. M., \& Hutchinson, S. J. (2003). Male drugs-related deaths in the fortnight after release from prison: Scotland, 1996-99. Addiction, 98(2), 185-190.

Bird, S. M., Fischbacher, C. M., Graham, L., \& Fraser, A. (2015). Impact of opioid substitution therapy for Scotland's prisoners on drug-related deaths soon after prisoner release. Addiction, $110(10), 1617-1624$. 
Bird, S. M., McAuley, A., Perry, S., \& Hunter, C. (2016). Effectiveness of Scotland's National Naloxone Programme for reducing opioid-related deaths: A before (2006-2010) versus after (2011-2013) comparison. Addiction, 111(5), 883-891.

Blair, T. (1993). Tony Blair is tough on crime, tough on the causes of crime. New Statesman. http://www. newstatesman.com/2015/12/archive-tony-blair-tough-crime-tough-causes-crime. Accessed 9 Dec 2016.

Bluthenthal, R. N., Lorvick, J., Kral, A. H., Erringer, E. A., \& Kahn, J. G. (1999). Collateral damage in the war on drugs: HIV risk behaviors among injection drug users. International Journal of Drug Policy, 10, 25-38.

Boys, A., Strang, J., \& Homan, C. (1997). Have drug workers in England received appropriate training? 1995 baseline data from a national survey. Drugs: Education, Prevention and Policy, 4(3), 297-304.

Burns, S. M., Brettle, R. P., Gore, S. M., Peutherer, J. F., \& Robertson, J. R. (1996). The epidemiology of HIV infection in Edinburgh related to the injecting of drugs: An historical perspective and new insight regarding the past incidence of HIV infection derived from retrospective HIV antibody testing of stored samples of serum. The Journal of Infection, 32, 53-62.

Connell, P., \& Strang, J. (2005). The origins of the new drug clinics of the 1960s. In J. Strang \& M. Gossop (Eds.), Heroin addiction and the British system (Vol. II, pp. 17-27). Oxford: Routledge.

Daily Mail. (n.d.) http://www.dailymail.co.uk/femail/article-439834/Girl-jailed-Olivia-Channon-died-speakstime.html

Department of Health. (1984). Drug abuse and dependence. Guidelines on clinical management. London: HMSO.

Department of Health. (1991). Drug misuse and dependence. Guidelines on clinical management. London: Her Majesty's Stationery Office (HMSO).

Department of Health. (1999). Drug misuse and dependence. Guidelines on clinical management. London: HMSO.

Department of Health. (2007). Drug abuse and dependence. Guidelines on clinical management. London: HMSO.

Disley, E., Donmall, M., Jones, A., Mason, T., Moretti, A., McSweeney, T., Millar, T., Rubin, J., Sutton, M., Taylor, J., \& Turnbull, P. (2014). Evaluation of the drugs and alcohol recovery payment by results pilot programme: Interim summary report. Manchester: National Drug Evidence Centre www.population-health. manchester.ac.uk/epidemiology/NDEC/newsandevents/news/PbRDR_Summary.pdf. Accessed 2 Jan 2017.

Drummond, C (2015). The Future of Addiction Psychiatry in 2015. Royal College of Psychiatrists. http://www. rcpsych.ac.uk/pdf/Drummond\%20Colin\%20-\%20Future\%20of\%20Addiction\%20May\%202015.pdf. Accessed 2 Jan 2017.

Duke, \& Thom. (2014). The role of evidence and the expert in contemporary processes of governance: The case of opioid substitution therapy in England. The International Journal on Drug Policy, 25(5), 964-971.

Enthoven, A.C. (1985). Reflections on the management of the National Health Service. Nuffield Provincial Hospitals Trust. http://www.nuffieldtrust.org.uk/sites/files/nuffield/publication/Reflections_on_the_ Management_of_NHS.pdf. Accessed 2 Jan 2017.

Farrell, M., \& Marsden, J. (2008). Acute risk of drug-related death among newly released prisoners in England and Wales. Addiction, 103(2), 251-255.

Finch, E., \& Ashton, M. (2005). Treatment to order: The new drug treatment and testing orders. In J. Strang \& M. Gossop (Eds.), Heroin addiction and the British system (Vol. II, pp. 187-197). Oxford: Routledge.

Francis, R. (2013). Report of the mid Staffordshire NHS foundation trust public inquiry. London: HMSO.

Gao, L., Dimitropoulou, P., Robertson, J. R., McTaggart, S., Bennie, M., \& Bird, S. M. (2016). Risk-factors for methadone-specific deaths in Scotland's methadone-prescription clients between 2009 and 2013. Drug and Alcohol Dependence, 167, 214-223.

Gossop, M. (2015). The National Treatment Outcomes Research Study (NTORS) and its influence on addiction treatment policy in the United Kingdom. Addiction, 110(S2), 50-53

Gossop, M., Griffiths, P., Powis, B., Williamson, S., \& Strang, J. (1996). Frequency of non-fatal heroin overdose: Survey of heroin users recruited in non-clinical settings. BMJ, 313, 402.

Gossop, M., Marsden, J., Stewart, D., \& Rolfe, A. (2000). Reductions in acquisitive crime and drug use after treatment of addiction problems: 1 year follow up outcomes. Drug and Alcohol Dependence, 58(1-2), 165-172.

Gossop, M., Marsden, J., Stewart, D., \& Kidd, T. (2003). The National Treatment Outcome Research Study (NTORS): 4-5 year follow-up results. Addiction, 98, 291-303.

Hall, W., Lynskey, M., \& Degenhardt, L. (2000). Trends in opiate-related deaths in the United Kingdom and Australia, 1985-1995. Drug and Alcohol Dependence, 57, 247-254.

Home Office. (1926). Report of the departmental committee on morphine and heroin addiction (the Rolleston report). London: HMSO.

Inter-Ministerial Group on Drugs (2012). Putting full recovery first: the recovery roadmap. London: Home Office. https://www.gov.uk/government/publications/putting-full-recovery-first-the-recovery-roadmap. Accessed 2 Jan 2017. 
Jones, A., Donmall, M., Millar, T., Moody, A., Weston, S., Anderson, Anderson, T., Gittins, M., Abeywardana, V., \& D'Souza, J. (2009). The drug treatment outcomes research study: Final outcomes report. London: Home Office.

Kidd, B. A., \& Ralston, G. E. (1993). Injecting drug users in Edinburgh. General practitioners reluctant to prescribe. $B M J, 306(6889), 1414-1414$.

Kingdon, J. W. (2014). Agendas, alternatives and public policies. Harlow: Pearson.

Leighton and Day (2013) The Evidence Debate. Druglink, May/June 2013. http://www.drugwise.org.uk/wpcontent/uploads/Evidence-debate.pdf. Accessed 2 Jan 2017.

Luger, L., Bathia, N., Alcorn, R., \& Power, R. (2000). Involvement of community pharmacists in the care of drug misusers: Pharmacy-based supervision of methadone consumption. The International Journal on Drug Policy, 11(3), 227-234.

Maynard, A., \& Dixon, M. (2016). Should the NHS abolish the purchaser-provider split. BMJ, 354, i3825.

McAuley, A., Best, D., Taylor, A., Hunter, C., \& Robertson, J. R. (2012). From evidence to policy: The Scottish national naloxone programme. Drugs: Education, Prevention and Policy, 19(4), 309-319.

McDonald, R., Hills, R., Hunter, C., Horsburgh, K., McAuley, A., Mundt-Leach, R., Small, S., Strang, J. (2016). Reducing deaths from opiate overdose: Take-home naloxone. In mistral. W (Ed.), Integrated approaches to drug and alcohol problems. Oxford: Routledge.

McKeganey, N., Morris, Z., Neale, J., \& Robertson, M. (2004). What are drug users looking for when they contact drug services: Abstinence or harm reduction? Drugs: Education, Prevention and Policy, 5, 423-435.

McKeganey, N., Bloor, M., Robertson, M., Neale, J., \& MacDougall, J. (2006). Abstinence and drug abuse treatment: Results from the rug outcome research in Scotland study. Drugs: Education, Prevention and Policy, 12(6), 537-550.

McKeganey, N. (2014). Clear rhetoric and blurred reality: The development of a recovery focus in UK drug treatment policy and practice. International Journal of Drug Policy, 25, 957-963.

Merrill, J., \& Ruben, S. (2005). Treating drug dependence in primary care: Reflecting on the problems as well as the potential. In J. Strang \& M. Gossop (Eds.), Heroin addiction and the British system (Vol. II, pp. 81-93). Oxford: Routledge.

Metzger, D. S., \& Zhang, Y. (2010). Drug treatment as HIV prevention: Expanding treatment options. Curr HIV/ AIDS, 7, 220-225.

Ministry of Health. (1965). Drug addiction. Second report of the interdepartmental committee. London: HMSO.

Mitcheson, M. (2005). Uncertainty within the drug clinics in the 1970s. In J. Strang \& M. Gossop (Eds.), Heroin addiction and the British system (Vol. II, pp. 41-52). Oxford: Routledge.

Mohammadi, D. (2015). Colin Drummond. The Lancet Psychiatry, 2(3), 208.

National Treatment Agency for Substance Misuse (2012). NTA supplementary note for HASC 2012 drug policy review. www.nta.nhs.uk/uploads/ntahascsupplementarynote-general.pdf. Accessed 2 Jan 2017.

Neale, J., Nettleton, S., \& Pickering, L. (2013). Does recovery-oriented treatment prompt heroin users prematurely into detoxification and abstinence programmes? Qualitative study. Drug and Alcohol Depend, 127, 163-169.

NICE. (2007a). Methadone and buprenorphine for the management of opioid dependence. NICE technology appraisal 114. London: National Institute for Health and Clinical Evidence.

NICE. (2007b). Drug misuse: opiate detoxification. NICE Clinical Guideline 52. London: National Institute for Health and Clinical Evidence.

NICE. (2007c). Naltrexone for the management of opioid dependence. NICE technology appraisal 115. London: National Institute for Health and Clinical Evidence.

NICE. (2007d). Drug misuse: Psychosocial interventions. NICE clinical guideline 51. London: National Institute for Health and Clinical Evidence.

Office of National Statistics (2015). Statistical bulletin: deaths related to drug poisoning in England and Wales: 2015 registrations. https://www.ons.gov.uk/peoplepopulationandcommunity/birthsdeathsandmarriages ?/deaths/bulletins/deathsrelatedtodrugpoisoninginenglandandwales/2015registrations. Accessed 9 Dec 2016.

O’Gara, C., Kearney, F., Best, D., Harris, J., Boys, A., Leonard, F., Kelleher, M., \& Strang, J. (2009). Substance misuse training among psychiatric doctors, psychiatric nurses, medical students and nursing students in a South London psychiatric teaching hospital. Drugs: Education, Prevention and Policy, 12(4), 327-336.

Paxton, R., Mullin, P., \& Beattie, J. (1978). The effects of methadone maintenance with opioid takers. A review and some findings from one British city. British Journal of Psychiatry, 132, 473-481.

Polkinghorne, J., Gossop, M., \& Strang, J. (2005). The government task force and its review of drug treatment services: The promotion of an evidence-based approach. In J. Strang \& M. Gossop (Eds.), Heroin addiction and the British system (Vol. II, pp. 198-205). Oxford: Routledge.

Robertson, J. R. (2005). The arrival of HIV. In J. Strang \& M. Gossop (Eds.), Heroin addiction and the British system (Vol. I, pp. 120-138). Oxford: Routledge.

Robertson, J. R., Bucknall, A. B. V., Welsby, P. D., Roberts, J. J., Inglis, J. M., Peutherer, J. F., \& Brettle, R. P. (1986). Epidemic of AIDS-related virus (HTLV-III/LAV) infection among intravenous drug abusers. BMJ, 292, 527-529. 
Scott, R. T. A., Gruer, L. D., Wilson, P., \& Wood, S. H. (1995). Methadone maintenance treatment: Scotland has an innovative scheme for encouraging GPs to manage drug misusers. BMJ, 310, 464 465 .

Scottish Drug Strategy Delivery Commission. (2013). Independent expert review of Opioid replacement therapies in Scotland: Delivering recovery. Edinburgh: Scottish Government.

Scottish Government. (2008). The road to recovery: A new approach to tackling Scotland's drug problem. Edinburgh: Scottish Government.

Scottish Office Home and Health Department. (1994). Report of the ministerial drugs task force. Drugs in Scotland: Meeting the challenge. London: HMSO.

Skidmore, C. A., Robertson, J. R., Roberts, J. J. (1989). Changes in HIV risk taking behaviour in intravenous drug users: A second follow up. Br J Addiction, 84, 695-696.

Stimson, G. V. (1995). AIDS and injecting drug use in the United Kingdom, 1987-1993: The policy response and the prevention of the epidemic. Social Science \& Medicine, 41(5), 699-716.

Stoke Sentinel. (n.d.) http://www.stokesentinel.co.uk/bac-o-connor-rehabilitation-centre-in-newcastle-facingclosure-due-to-800-000-funding-cut/story-29875269-detail/story.html. Accessed 2 Jan 2017.

Strang, J. (2005). AIDS and drug misuse in the UK. In J. Strang \& M. Gossop (Eds.), Heroin addiction and the British system (Vol. I, pp. 196-210). Oxford: Routledge.

Strang, J. (1998). AIDS and drug misuse in the UK - 10 years on: Achievement, failings and new harm reduction opportunities. Drugs: Education, Prevention and Policy, 5(3), 293-304.

Strang, J. (2010). Interview regarding Griffith Edwards, Maudsley, Phoenix, and his early field interest. http://www.fead.org.uk/video/john-strang-on-griffith-edwards-maudsley-phoenix-and-his-early-fieldinterest/. Accessed 2 Jan 2017.

Strang, J. (2015). Death matters: Understanding heroin/opiate overdose risk and testing potential to prevent deaths. Addiction, 110 supplement 2, 27-35.

Strang, J. \& Gossop, M. (ed.) (2005). Heroin addiction and the British system, Vol. I. Oxford: Routledge.

Strang, J., Darke, S., Hall, W., Farrell, M., \& Ali, R. (1996a). Heroin overdose: The case for take-home naloxone. $B M J, 312,1435$.

Strang, J., Drummond, C., McNeill, A., Lader, M., Marsden, J. (2014). Addictions, dependence and substance misuse. in The Annual Report of the Chief Medical Officer 2013. London: Department of Health. https:/www.gov.uk/government/uploads/system/uploads/attachment_data/file/413196/CMO_web_doc.pdf. Accessed 2 Jan 2017.

Strang, J., Hall, W., Hickman, M., \& Bird, S. M. (2010). Impact of supervision of methadone consumption on deaths related to methadone overdose (1993 - 2008): Analyses using OD4 index in England and Scotland. $B M J, 341, \mathrm{c} 4851$.

Strang, J., Manning, V., Mayet, S., Ridgem, G., Best, D., \& Sheridan, J. (2007). Does prescribing for opiate addiction change after national guidelines? Methadone and buprenorphine prescribing to opiate addicts by general practitioners and hospital doctors in England, 1995-2005. Addiction, 102, 761-770.

Strang, J., Powis, B., Best, D., Vingoe, L., Griffiths, P., Taylor, C., Welch, S., \& Gossop, M. (1999). Preventing opiate overdose fatalities with take-home naloxone: Pre-launch study of possible impact and acceptability. Addiction, 94(2), 199-204.

Strang, J., Ruben, S., Farrell, M., Whitton, J., Keaney, F., \& Gossop, M. (2005). The history of prescribing heroin and other injectable drugs as addiction treatment in the UK. In J. Strang \& M. Gossop (Eds.), Heroin addiction and the British system (Vol. II, pp. 1-16). Oxford: Routledge.

Strang, J., Sheridan, J., \& Barber, N. (1996b). Prescribing injectable and oral methadone to opiate addicts. Results from the 1995 national postal survey of community pharmacies in England and Wales. BMJ, 313, $270-272$.

Sheridan, J. (2005). Needle exchange in Britain. In J. Strang \& M. Gossop (Eds.), Heroin addiction and the British system (Vol. II, pp. 145-155). Oxford: Routledge.

Sondhi, A., Ryan, G., \& Day, E. (2016). Stakeholder perceptions and operational barriers in the training and distribution of take-home naloxone within prisons in England. Harm Reduction J, 13(5). https://oi. org/10.1186/s12954-016-0094-1.

Turner, D. (2005). The development of the voluntary sector: No further need for pioneers? In Strang, J. and Gossop, M. (Ed.), Heroin addiction and the British system. I. Oxford: Routledge.

UK Drug Policy Commission Recovery Consensus Group (2008). A vision of recovery. London: UK Drug Policy Commission. http://www.ukdpc.org.uk/wp-content/uploads/Policy\%20report\%20-\%20A\%20 vision\%20of\%20recovery_\%20UKDPC\%20recovery\%20consensus\%20group.pdf. Accessed 2 Jan 2017.

WHO Collaborative Study Group. (1993). An international comparative study of HIV prevalence and risk behaviour among drug injectors in 13 cities. Bull. Narcotics, XLV, 19.

Willis, J. (2005). The new drug clinics of 1968. In Strang, J. and Gossop, M. (Ed.), Heroin Addiction and the British System. II. Oxford: Routledge.

Zador, D., Kidd, B., Hutchinson, S., Taylor, A., Hickman, M., Fahey, T., Rome, A., \& Baldacchino, A. (2003). National Investigation into drug related deaths in Scotland, 2003. Edinburgh: Scottish Executive. 